BMJ Open Sport \& Exercise Medicine

\title{
Professional footballers have a limited understanding of the precompetition medical assessment and the possible outcomes including disqualification: a cross-sectional survey
}

Thomas J Chin (D) , ${ }^{1,2}$ Arier C L Lee, ${ }^{3}$ Mark L Fulcher ${ }^{4,5}$

To cite: Chin TJ, Lee ACL, Fulcher ML. Professional footballers have a limited understanding of the precompetition medical assessment and the possible outcomes including disqualification: a crosssectional survey. BMJ Open Sport \& Exercise Medicine 2021;7:e001006. doi:10.1136/ bmjsem-2020-001006

- Additional material is published online only. To view, please visit the journal online (http://dx.doi.org/10.1136/ bmjsem-2020-001006).

Accepted 22 February 2021

Check for updates

(c) Author(s) (or their employer(s)) 2021. Re-use permitted under CC BY-NC. No commercial re-use. See rights and permissions. Published by BMJ.

${ }^{1}$ Anglesea Sports Medicine, Hamilton, New Zealand ${ }^{2}$ Summit Sports Medicine, Mount Maunganui, New Zealand ${ }^{3}$ Department of Epidemiology and Biostatistics, The University of Auckland Faculty of Medical and Health Sciences, Auckland, New Zealand

${ }^{4}$ Axis Sports Medicine Specialists, Auckland, New Zealand

${ }^{5}$ University of Auckland, Auckland, New Zealand

Correspondence to Dr Thomas J Chin; tchinj@gmail.com

\section{ABSTRACT}

Objectives To determine professional footballers' level of understanding of the purpose of the precompetition medical assessment (PCMA) and to evaluate their knowledge of potential outcomes following a PCMA, including disqualification.

Methods Professional footballers from the Australasian A-League and Westfield W-League were asked to complete a 25-question survey. The relationship between dichotomised outcomes and explanatory variables was analysed with multivariate logistic regression; $p<0.05$ was considered statistically significant.

Results A total of 212 players participated (response rate $=48.8 \%$ ). Most respondents selected ' $T o$ detect medical conditions that may affect performance' and 'To detect current injuries' $(n=137,64.6 \% ; n=130$, $61.3 \%$ ) as the purpose of a PCMA. Approximately onethird $(n=74,38.1 \%)$ were neutral or believed that a normal PCMA prevented cardiac arrest. Receiving more PCMAs $(p<0.0003)$ and receiving an explanation during their PCMA ( $p=0.0175)$ led to greater awareness of the assessment's limitations. Most participants did not know the definitions of syncope $(n=181,93.3 \%)$ or Marfan syndrome $(n=183,94.3 \%)$. Fifty players $(28.1 \%)$ did not know that disqualification was a possible outcome of a PCMA, and younger players were less aware of this possible outcome $(p=0.0216)$.

Conclusion Professional footballers appear to have a limited understanding of the purpose of a PCMA, emphasising the musculoskeletal system and performance. They also appear unfamiliar with the components of the PCMA and medical terms. Finally, many are unaware that disqualification can result from an abnormal PCMA. Player health knowledge must be improved; the informed consent process appears an ideal time to provide this education.

\section{INTRODUCTION}

Conducting a precompetition medical assessment (PCMA) is accepted, and routine practice among elite-level sportspeople. ${ }^{12}$ The death of Marc Vivien Foé on the field of play in 2003 brought sudden cardiac death into

\section{What are the new findings?}

Football players have a limited understanding of the purpose of a precompetition medical assessment (PCMA) and the medical terms that are involved in the health questionnaire.

- Players need clear information about the potential consequences of the PCMA process, including disqualification. A normal PCMA does not mean that they cannot have a sudden cardiac arrest.

- Medical professionals and organisations involved in professional sport must provide better education and ensure informed consent is obtained before conducting a PCMA.

the spotlight among footballers. His death resulted in FIFA introducing a structured PCMA programme. ${ }^{3}$ This became mandatory for all FIFA tournaments in the men's game before the 2006 FIFA World Cup and was introduced to female and youth World Cup competitions in 2007 and 2010. ${ }^{45}$ The FIFA PCMA has a standardised format, typically completed by the team doctor. This involves a medical history, physical examination, 12-lead ECG, echocardiogram and a panel of blood tests. ${ }^{3}$ This type of assessment is also widely used in other sporting codes. ${ }^{6}$ The PCMA has a range of functions. However, a key purpose is to detect conditions that may predispose to adverse medical events, including sudden cardiac arrest (SCA). ${ }^{1}$ Other important roles include identifying other medical problems, injury risk factors and ensuring current issues are managed appropriately. ${ }^{7}$

Over the past decade, several papers have been published relating to the PCMA process. These primarily relate to the assessment's ability to identify pathology, the practicalities of conducting the assessment and the conditions the assessment aims to identify. ${ }^{18}$ While the use of the PCMA, especially regarding the 
cardiovascular assessment, has increased over the past two decades, there is little data evaluating athlete experience with the assessment. ${ }^{9}$ The available data suggest studentathletes see no value in preparticipation screening and believe the assessment's main role is to prevent injury. In contrast, elite French athletes believe not enough emphasis is placed on injuries. ${ }^{10} 11$ These two papers were published in the 1990s and therefore may have limited current relevance given the inclusion of an ECG, and echocardiogram in the PCMA is a relatively new development. ${ }^{12}$ The ECG was introduced by the European Society of Cardiology in 2005 but remains a controversial talking point. ${ }^{13}$ The only study solely involving footballers evaluated potential distress caused by the assessment. ${ }^{14}$ These authors found that most players felt the assessment was necessary and felt more confident playing having had a PCMA. A small number (16\%) were afraid their PCMA might have personal health consequences and $13 \%$ were afraid of disqualification. ${ }^{14}$

Despite consenting to undergo a PCMA, it has been questioned whether elite athletes understand this assessment's purpose. ${ }^{15}$ To our knowledge, there are no studies that evaluate what elite or professional football players know about the purpose of a PCMA and its potential outcomes. This study's primary aim is to determine the level of understanding of professional footballers in Australasia about the purpose and objectives of a PCMA. A secondary aim is to determine their knowledge of the potential outcomes following a PCMA, particularly disqualification. We believe that this study may ultimately enhance the PCMA process for players by improving their understanding of the process, better preparing them for any potential adverse findings that may arise and by respecting their need for autonomy.

\section{METHODS}

\section{Participants and procedures}

Between January and May 2019, players based in Australia and New Zealand and competing in the A-League and Westfield W-League, Australasia's men's and women's professional football leagues, were invited to complete a short anonymised questionnaire. An invitation to complete the survey, along with a participant information sheet, was sent to the team doctor and physiotherapists of the 10 men's and nine women's clubs. A total of 258 male and 176 female players were then invited to participate via their team medical staff. Paper and electronic versions of the survey (administered via a secure online platform) were offered. To be eligible, players had to be members of an A-League club or Westfield W-League club for the 2018/2019 season. Players aged less than 16 years were excluded.

\section{Survey}

The survey tool was developed after a narrative review to try to identify papers related to this subject. A systematic review was not performed. Very little data were identified that could be used to aid the survey design. Existing data were incorporated where possible (see online supplemental material). The survey featured 25 questions and included questions about demographic factors, playing experience and questions pertaining to the PCMA.

\section{Primary and secondary outcomes}

The primary outcome was the relative frequency distribution of players' beliefs regarding the purposes of a PCMA. Relative frequency distributions were further obtained for knowledge of the medical terms, syncope and Marfan syndrome, and knowledge of potential disqualification following a PCMA. Using a Likert scale, players were also asked to assess the statement 'If you have had a normal PCMA you cannot have a cardiac arrest'. This was treated as a dichotomous variable allowing relative frequency calculations.

\section{Data analysis}

Survey responses submitted on paper were transferred to the online platform. Data were downloaded and checked for accuracy before statistical analysis using SAS V.9.4 (SAS Institute Inc, Cary, North Carolina, USA). Median and range were presented for continuous variables, while count and percentage were used for categorical variables. Multivariate logistic regression was used to analyse the relationship between dichotomised outcomes and explanatory variables. $\mathrm{P}<0.05$ was considered statistically significant.

\section{Patient and public involvement}

A small cohort of players and medical staff were invited to provide feedback on the survey instrument's development and delivery. Members of the general public were not invited to comment on the study as they were not directly involved in this research project.

\section{RESULTS}

\section{Participants}

There were 212 survey respondents with an overall response rate of $48.8 \%: 55.4 \%(\mathrm{n}=143)$ for the A-League and $39.2 \%(\mathrm{n}=69)$ for the Westfield W-League. A total of 34 incomplete surveys were submitted. These partial responses were included in the analysis leading to different denominators across the survey. Most participants were male $(\mathrm{n}=138,65.1 \%)$. The median age was 24 years across the group, with a median of 5 years of professional playing experience (minimum=1 year, maximum $=20$ years .

\section{PCMA receipt}

Nearly half of the participants had received more than two PCMAs ( $\mathrm{n}=94,48.5 \%)$. Twenty-three $(11.9 \%)$ participants stated that they have never had a PCMA and $17.5 \%$ $(n=34)$ were unsure whether they had received one previously. This is reflected in $38.7 \%(\mathrm{n}=75)$ of respondents stating that they either had not heard of or were unsure whether they had heard of the term ' $P C M A$ ' or 'pre-competition competition medical assessment'. 


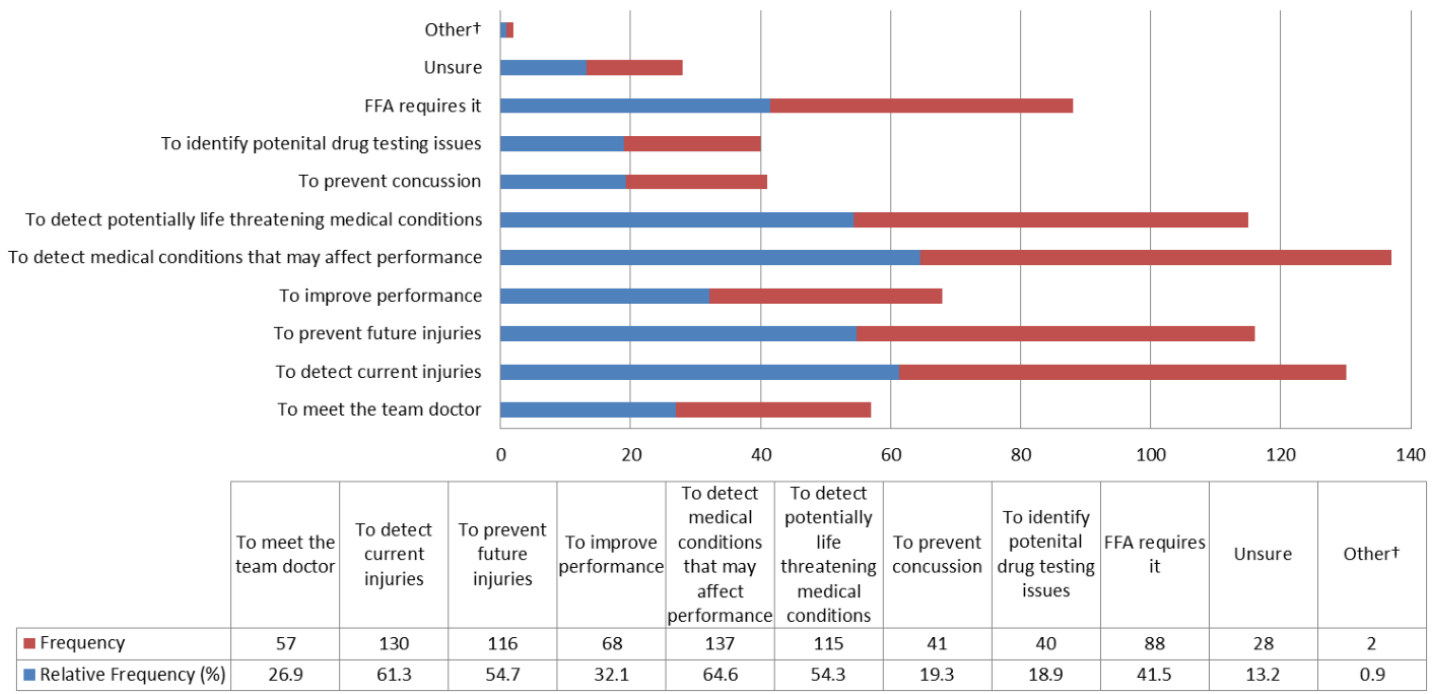

Figure 1 Stacked bar chart displaying frequency and relative frequency of player responses to the survey question: 'What do you believe the purposes of the PCMA are?' †Other responses: 'To have a baseline to go off' and 'To protect the club'. FFA, Football Federation Australia.

\section{Purposes of the PCMA}

A majority of participants selected 'To detect medical conditions that may affect performance' and 'To detect current injuries' $(n=137,64.6 \% ; n=130,61.3 \%)$ as being the purpose of a PCMA. Other responses relating to the purpose of the PCMA are illustrated in figure 1.

\section{Awareness of PCMA limitations}

Many participants $(\mathrm{n}=84,43.3 \%)$ were neutral about whether they could safely play football without a PCMA. The majority disagreed or strongly disagreed that a PCMA was protective against suffering a cardiac arrest, disagreeing with the statement 'If you have had a normal PCMA you cannot have a cardiac arrest' $(\mathrm{n}=120,61.9 \%)$. A large number $(\mathrm{n}=82,42.5 \%)$ reported they were not given any information about why the PCMA was being performed or were unsure whether they had received an explanation. Almost a quarter completed the medical history section of the PCMA on their own $(n=42,22.3 \%)$; however, most had some form of physician or physiotherapist involvement $(\mathrm{n}=146,77.7 \%)$.

Multivariate logistic regression revealed that disagreeing with the statement 'If you have had a normal PCMA you cannot have a cardiac arrest' was significantly associated with the total number of PCMAs undertaken by the athlete $(\mathrm{p}<0.0003)$ and receiving information on why the PCMA was being completed $(p=0.0175)$. An increase in one PCMA increased the odds of disagreeing by $70.9 \%$ (OR=1.71, 95\% CI 1.28 to 2.29 ). Age, years of professional playing experience and receiving assistance during the history section of PCMA had no statistically significant association with this statement.

\section{Health knowledge}

Very few $(n=13,6.7 \%)$ participants knew the definition of syncope or what Marfan syndrome was $(n=11,5.7 \%)$. Approximately one-third $(n=18,34.6 \%)$ of players who had never heard of the PCMA $(n=52)$ reported they had never received a PCMA. The majority $(n=166,85.6 \%)$ believed their team doctor performed a physical examination on them as part of the PCMA. Only a very small number reported that they did not receive or were unsure whether they received an ECG $(\mathrm{n}=15,7.8 \%)$ or echocardiogram $(n=25,13 \%)$. Further analysis of these PCMA individual components is displayed in table 1 .

\section{Knowledge of disqualification}

A total of $28.1 \%(n=50)$ did not know disqualification from playing football was a possible outcome following a PCMA. Multivariate logistic regression revealed age was highly associated with knowledge of disqualification $(\mathrm{p}=0.0216)$ with a weak association with receiving more PCMAs ( $\mathrm{p}=0.0665)$ (table 2).

Almost half of the participants $(n=88,49.4 \%)$ were neutral, disagreed or strongly disagreed with the statement 'Should a problem be identified on your PCMA and you were advised not to play football, would you comply with this advice by stopping playing?? The majority would not withhold information to avoid disqualification $(n=153,86 \%)$.

A summary of the study's main findings for each league, highlighting responses for male and female players, can be found in table 3 .

\section{DISCUSSION}

To our knowledge, the level of understanding about the player experience and purpose of a PCMA has not been evaluated among professional footballers. The results of the current study suggest that these players have a limited understanding of the purpose of the PCMA, that the structure of the PCMA process could be improved and that many players are unaware of the potential outcomes of the PCMA process (including disqualification). 
Table 1 The association between individual PCMA components (physical examination, ECG and echocardiogram) and a player hearing of the term PCMA and believing they never received a PCMA

\begin{tabular}{|c|c|c|c|c|}
\hline & \multicolumn{2}{|c|}{ Physical examination } & \multirow[b]{2}{*}{ Total } & \multirow{2}{*}{$\frac{\chi^{2} \text { test }}{P \text { value }}$} \\
\hline & No/unsure & Yes & & \\
\hline & $\mathrm{N}(\%)$ & $\mathrm{N}(\%)$ & $\mathbf{N}$ & \\
\hline Have heard of the term PCMA before & & & & 0.002 \\
\hline No & $12(23.08)$ & 40 (76.92) & 52 & \\
\hline Unsure & 7 (30.43) & $16(69.57)$ & 23 & \\
\hline Yes & $9(7.56)$ & $110(92.44)$ & 119 & \\
\hline Have never received a PCMA & & & & 0.02 \\
\hline No & $21(12.28)$ & $150(87.72)$ & 171 & \\
\hline \multirow[t]{2}{*}{ Yes } & $7(30.43)$ & $16(69.57)$ & 23 & \\
\hline & ECG & & Total & Fisher's exact test \\
\hline Have heard of the term PCMA before & & & & 0.03 \\
\hline No & $6(11.54)$ & $46(88.46)$ & 52 & \\
\hline Unsure & $4(18.18)$ & $18(81.82)$ & 22 & \\
\hline Yes & $5(4.24)$ & $113(95.76)$ & 118 & \\
\hline Have never received a PCMA & & & & 0.003 \\
\hline No & $9(5.29)$ & $161(94.71)$ & 170 & \\
\hline \multirow[t]{2}{*}{ Yes } & $6(27.27)$ & $16(72.73)$ & 22 & \\
\hline & Echocardi & & Total & \\
\hline Have heard of the term PCMA before & & & & $0.0126^{*}$ \\
\hline No & $10(19.23)$ & $42(80.77)$ & 52 & \\
\hline Unsure & $6(27.27)$ & $16(72.73)$ & 22 & \\
\hline Yes & $9(7.63)$ & $109(92.37)$ & 118 & \\
\hline Have never received a PCMA & & & & $0.003 \dagger$ \\
\hline No & $17(10)$ & $153(90)$ & 170 & \\
\hline Yes & $8(36.36)$ & $14(63.64)$ & 22 & \\
\hline
\end{tabular}

${ }^{*} \chi^{2}$ test.

†Fisher's exact test.

PCMA, precompetition medical assessment.

\section{Clear communication with universal health literacy precautions}

Consistent with existing data, most participants in the current study believe that the main purpose of the PCMA is to address musculoskeletal pathology or to improve performance. $^{10}{ }^{11}$ Only $54.3 \% \quad(n=115)$ of footballers believed this assessment was 'To detect potentially life threatening medical conditions'. This contrasts with sporting bodies' intent and beliefs, like FIFA, and many of the clinicians who perform these assessments. ${ }^{137}$ While the FIFA PCMA includes a range of medical and musculoskeletal assessments, it is primarily designed to detect potentially fatal cardiac abnormalities. ${ }^{3}$

In addition to a lack of understanding of the purpose of the PCMA, many players did not understand the content of the assessment. Very few players knew the correct definition of syncope $(\mathrm{n}=13,6.7 \%)$ and Marfan syndrome $(\mathrm{n}=11,5.7 \%)$ despite these terms being used in the FIFA PCMA. ${ }^{16}$ Given that almost a quarter $(22.3 \%)$ completed the history section on their own, without supervision, this means that recorded responses may be incorrect and raises concern about the accuracy of other responses. It should also be noted that receiving supervision and/or assistance did not appear to be associated with improved knowledge of the assessment's limitations $(p=0.1403)$, suggesting that this information's delivery needs to be improved. In other areas of medicine, it has been shown that limited health literacy contributes to poor health outcomes and that doctors frequently underestimate this impact. ${ }^{17}$ We suggest simple universal health literacy precautions are used to aid in delivering understandable information during the PCMA. The removal of medical jargon from the PCMA is one such step, with the communication of information in plain language. ${ }^{17}$ The FIFA PCMA has a Flesch Reading Ease score of 6.1, placing it into the 'very difficult' readability range. ${ }^{18}$ This clearly needs improvement. It is also known that $40 \%-80 \%$ of the medical information patients receive is forgotten immediately and that nearly half of retained information is incorrect. ${ }^{19}$ The teach-back method may be a useful tool to ensure players understand the information they have received and could readily be implemented in a 
Table 2 The association between different effects and knowledge of disqualification as a potential outcome following a PCMA and subanalysis

\begin{tabular}{|c|c|c|}
\hline Effect & $\operatorname{Pr}>\chi^{2}$ & \\
\hline Player age & 0.0216 & \\
\hline Playing experience & 0.1885 & \\
\hline Total PCMAs received & 0.0665 & \\
\hline Explanation about the PCMA & 0.6944 & \\
\hline $\begin{array}{l}\text { Medical assistance (team doctor } \\
\text { or physiotherapist) during the } \\
\text { PCMA's history component }\end{array}$ & 0.1774 & \\
\hline \multicolumn{3}{|c|}{ OR estimates } \\
\hline Effect & $\begin{array}{l}\text { Point } \\
\text { estimate }\end{array}$ & $\begin{array}{l}95 \% \text { Wald } \\
\text { Confidence limits }\end{array}$ \\
\hline Player age & 1.203 & 1.027 to 1.408 \\
\hline Total PCMAs received & 1.316 & 0.982 to 1.766 \\
\hline
\end{tabular}

An increase in 1 year of age increases the odds of knowing disqualification from playing football was a possible outcome following a PCMA by $20.3 \%$ (OR=1.203, 95\% Cl 1.027 to 1.408$)$. For every additional PCMA conducted for a player, this increases the odds of this knowledge by $31.6 \%(\mathrm{OR}=1.316,95 \% \mathrm{Cl} 0.982$ to 1.766$)$ up to three total PCMAs.

PCMA, precompetition medical assessment.

football-medicine context. ${ }^{17}$ If a player understands what they have been told, they can 'teach-back' the information accurately to their clinician. These communication skills have been employed in other areas of medicine and have been shown to improve patient understanding and enhance treatment adherence. ${ }^{20}$
A lack of understanding of the PCMA process could have significant consequences in particular, potentially impeding the diagnosis of cardiac conditions that may predispose players to SCA. These conditions can be difficult to diagnose. It is well known a normal PCMA result does not completely rule out the possibility that a player can subsequently have an SCA or be diagnosed with a cardiac condition. ${ }^{21}$ This is highlighted by a Norwegian study that found $1 \%$ of male footballers subsequently suffered a severe cardiovascular event despite having had a negative PCMA. $^{22}$ Three players in this sample had experienced, and ignored, warning symptoms. The authors concluded that negative screening might unjustifiably reassure athletes, cause them to ignore symptoms and avoid medical attention. ${ }^{22}$ Our findings appear to support this hypothesis with almost $40 \%$ of players being 'neutral' towards or agreeing with the statement 'If you have had a normal PCMA you cannot have a cardiac arrest'.

Given this potential uncertainty, the assessment's limitations must be clearly outlined, that players have a good understanding of this problem and that this is clearly documented. The real-world impact that this could have is highlighted by a legal case that held a medical team liable for a poor outcome suffered by one of their players. Radwan Hamed, a youth professional football player, suffered an SCA despite having a PCMA. ${ }^{23}$ While several factors contributed to this outcome, the judge found that a large contributor was poor communication between the medical team and the player's family. ${ }^{23}$ This again stresses the importance of communicating the PCMA's

Table 3 Primary and secondary survey outcomes highlighting response differences between the two leagues

\begin{tabular}{|c|c|c|c|}
\hline & & A-League & Westfield W-League \\
\hline & & N (\%) & $\mathrm{N}(\%)$ \\
\hline & Median age (years) & 25 & 23 \\
\hline & Median playing experience (years) & 6 & 5 \\
\hline & Have heard of the term PCMA (no/unsure) & $57(44.5)$ & $18(27.3)$ \\
\hline & Have never received a PCMA & $17(13.3)$ & $6(9.1)$ \\
\hline Perceived purpose of the PCMA & To detect current injuries & $81(56.6)$ & $49(71)$ \\
\hline & To prevent future injuries & $67(46.9)$ & $49(71)$ \\
\hline & $\begin{array}{l}\text { To detect medical conditions that may affect } \\
\text { performance }\end{array}$ & $84(58.7)$ & $53(76.8)$ \\
\hline & $\begin{array}{l}\text { To detect potentially life threatening medical } \\
\text { conditions }\end{array}$ & $75(52.4)$ & $40(58)$ \\
\hline If you have had a normal PCMA & Strongly agree/agree/neutral & $59(46.1)$ & $15(22.7)$ \\
\hline & Given information about the PCMA (no/unsure) & $61(47.7)$ & $21(32.3)$ \\
\hline Knowledge of medical terms (no/ & Syncope & $123(96.1)$ & $58(87.9)$ \\
\hline & Marfan syndrome & $124(96.9)$ & $59(89.4)$ \\
\hline Receipt of cardiac investigations & ECG & $10(7.8)$ & $5(7.8)$ \\
\hline & Echo & $18(14.1)$ & 7 (10.9) \\
\hline & Did not know disqualification was possible & $33(27.3)$ & $17(29.8)$ \\
\hline
\end{tabular}

PCMA, precompetition medical assessment. 
limitations and that it cannot predict or prevent adverse cardiac outcomes with certainty. It also re-enforces the need to ensure players, and where relevant, their parents are made aware of any potentially abnormal findings and the potential risks they may face.

\section{Disqualification from play}

Approximately one-third of respondents did not know disqualification from football could result from their PCMA. Older players were more likely to be aware of this potential outcome which may reflect their greater exposure to PCMAs or an understanding of the financial impact of this outcome. The importance of education is clear. It is possible that this difficult conversation is being downplayed by clinicians performing the assessment, with an over-reliance on written consent forms. It is known that consent forms alone are ineffective at communicating risks. ${ }^{24} \mathrm{~A}$ verbal discussion should occur that clearly explains the potential for disqualification and other potential outcomes, and this should be clearly documented.

There is no legal precedent holding a physician accountable for denying an athlete medical clearance for a known cardiovascular abnormality. However, team doctors still have an ethical, medical and legal obligation to outline all risks. ${ }^{25}$ While most participants state they would not withhold information to avoid disqualification, a lack of reporting has been documented among sportspeople in different contexts. ${ }^{26}$ For example, this has been widely reported among athletes who have sustained a sports-related concussion (SRC).$^{26}$ There may be various external factors driving this behaviour during a PCMA that are similar to those that influence the reporting of SRC. External pressure from coaches, teammates, family and fans may be a factor and the more obvious economic pressures. ${ }^{26}$ More simply, athletes may just wish to continue to play and not realise such symptoms may have life-altering consequences. ${ }^{27}$ This again emphasises the importance of education.

Of note, it is the authors' experience that most medical staff associated with professional football teams in Australasia are part-time employees. This may impact their ability to participate fully in the PCMA process and may negatively influence players' knowledge on the purpose of the PCMA.

\section{A standardised PCMA template is needed}

A PCMA is compulsory for all football players competing in the A-League and Westfield W-League. Despite this being a prerequisite for play, some players report not having the assessment or components of the assessment. Conversely, several players believed a PCMA was not conducted but recalled receiving an ECG or echocardiogram. Again, this conflicting information may highlight a lack of understanding or reflect the level of importance towards the PCMA. Part of this confusion, however, may lie with the PCMA process itself. There is currently no standardised template for players competing in these leagues. Consequently, individual clubs and clinicians may have different processes, and some tests that are recommended by sporting bodies, like FIFA, are not being conducted. Given there is also variation in the PCMA protocols suggested by different international sporting bodies, this is perhaps not surprising. ${ }^{16-8}$ Developing an evidence-based standardised format, with minimal medical jargon and input from players, is suggested. This may help to minimise confusion, ensuring all players have access to the same level of care.

\section{Strengths and limitations}

A major strength of the current paper is that it is the first study to investigate the level of understanding about the purpose of a PCMA among professional footballers or athletes of other sporting codes since the introduction of cardiac screening. A potential limitation is that while the results represent a relatively large sample of both male and female players, across two countries, they may not be generalisable to all professional players and may not be generalisable to athletes in other sports. It is also important to highlight a disproportionate bias towards male respondents that may limit the generalisability to female players. This was due to the timing of the survey. The Westfield W-League was nearing the season's end, whereas only half of the A-League fixtures had elapsed before the survey was circulated. Consequently, statistical analysis stratifying for gender was not possible. Although not statistically significant, we note that players from the Westfield W-League appeared to be more aware of the PCMA's limitations with regards to preventing SCA. Finally, the survey instrument itself, as well as the quantitative study design, are potential limitations. The tool used in this study is not validated and suffers from all the limitations of quantitative design, including recall bias. A qualitative study design would likely better explore the players' understanding and beliefs. Expanding the study to a larger sample, potentially including athletes from other sports and more female participants, might also be considered to further evaluate the PCMA process and validate the survey instrument.

\section{CONCLUSION}

The current study has demonstrated that there appears to be a lack of understanding about the purpose of the PCMA, the process and the potential outcomes following the assessment. Sporting organisations, team medical staff and the players themselves all have an important role to play in this. Better systems and education of players are needed as it is essential that players are well informed and involved during all medical consults. It is suggested that the PCMA process is reviewed at both an individual and organisational level.

Acknowledgements The authors highly appreciate the cooperation of all players who volunteered their time to fill in the questionnaire. We also express our gratitude to all club doctors and physiotherapists for distributing the questionnaire and helping to achieve a high response rate. Finally, we acknowledge the contributions of Dr Mark Jones of Football Federation Australia and his colleagues 
Rob Duffield and Alan McCall of the University of Technology Sydney in contributing to the delivered questionnaire.

Contributors TJC and MLF contributed to the study conception and design. Material preparation and data collection were performed by TJC. The analysis was performed by ACLL. TJC drafted the first version of the manuscript, and all authors contributed intellectually, providing feedback on previous versions of the manuscript.

Funding The authors have not declared a specific grant for this research from any funding agency in the public, commercial or not-for-profit sectors.

Competing interests MLF is the medical director for New Zealand Football and sits on the medical committee for FIFA.

Patient consent for publication Not required.

Ethics approval The study protocol was reviewed by the New Zealand Health and Disability Ethics Committees (reference number 18/CEN/128).

Provenance and peer review Not commissioned; externally peer reviewed.

Data availability statement Data are available on reasonable request. The data that support the findings of this study are available on request from the corresponding author, TJC.

Supplemental material This content has been supplied by the author(s). It has not been vetted by BMJ Publishing Group Limited (BMJ) and may not have been peer-reviewed. Any opinions or recommendations discussed are solely those of the author(s) and are not endorsed by BMJ. BMJ disclaims all liability and responsibility arising from any reliance placed on the content. Where the content includes any translated material, BMJ does not warrant the accuracy and reliability of the translations (including but not limited to local regulations, clinical guidelines, terminology, drug names and drug dosages), and is not responsible for any error and/or omissions arising from translation and adaptation or otherwise.

Open access This is an open access article distributed in accordance with the Creative Commons Attribution Non Commercial (CC BY-NC 4.0) license, which permits others to distribute, remix, adapt, build upon this work non-commercially, and license their derivative works on different terms, provided the original work is properly cited, appropriate credit is given, any changes made indicated, and the use is non-commercial. See: http://creativecommons.org/licenses/by-nc/4.0/.

ORCID iD

Thomas J Chin http://orcid.org/0000-0002-5335-0114

\section{REFERENCES}

1 Corrado D, Pelliccia A, Bjørnstad HH, et al. Cardiovascular preparticipation screening of young competitive athletes for prevention of sudden death: proposal for a common European protocol. consensus statement of the study group of sport cardiology of the Working group of cardiac rehabilitation and exercise physiology and the Working group of myocardial and pericardial diseases of the European Society of cardiology. Eur Heart J 2005;26:516-24.

2 Pelliccia A, Maron BJ. Preparticipation cardiovascular evaluation of the competitive athlete: perspectives from the 30-year Italian experience. Am J Cardiol 1995;75:827-9.

3 Kramer EB, Dvorak J, Schmied C, et al. F-MARC: promoting the prevention and management of sudden cardiac arrest in football. $\mathrm{Br}$ $J$ Sports Med 2015;49:597-8.

4 Thünenkötter T, Schmied C, Grimm K, et al. Precompetition cardiac assessment of football players participating in the 2006 FIFA World cup Germany. Clin J Sport Med 2009;19:322-5.

5 Keller DI, Bizzini M, Feddermann N, et al. Fifa women's world cup 2011: pre-competition medical assessment of female Referees and assistant Referees. Br J Sports Med 2013;47:179-81.

6 Orchard JJ, Orchard JW, La Gerche A, et al. Cardiac screening of athletes: consensus needed for clinicians on indications for followup echocardiography testing. Br J Sports Med 2020;54:936-8.
7 Ljungqvist A, Jenoure P, Engebretsen L, et al. The International Olympic Committee (IOC) consensus statement on periodic health evaluation of elite athletes March 2009. Br J Sports Med 2009:43:631-43.

8 Maron BJ, Thompson PD, Ackerman MJ, et al. Recommendations and considerations related to preparticipation screening for cardiovascular abnormalities in competitive athletes: 2007 update. Circulation 2007;115:1643-55

9 Schmied C, Notz S, Cribari M, et al. Cardiac pre-competiton screening in Swiss athletes. current situation in competitive athletes and short-time assessment of an exemplary local screening program. Swiss Med Wkly 2012;142:w13575.

10 Carek PJ, Futrell M. Athletes' view of the preparticipation physical examination. attitudes toward certain health screening questions. Arch Fam Med 1999;8:307-12.

11 Laure P. High-level athlete's impressions of their preparticipation sports examination. J Sports Med Phys Fitness 1996;36:291-2.

12 Drezner JA, O'Connor FG, Harmon KG, et al. AMSSM position statement on cardiovascular Preparticipation screening in athletes: current evidence, knowledge gaps, recommendations and future directions. Br J Sports Med 2017;51:153-67.

13 Mosterd A. Pre-participation screening of asymptomatic athletes : "Don't do stupid stuff". Neth Heart J 2018;26:123-6.

14 Solberg EE, Bjørnstad TH, Andersen TE, et al. Cardiovascular pre-participation screening does not distress professional football players. Eur J Prev Cardiol 2012;19:571-7.

15 Magavern EF, Finocchiaro G, Sharma S, et al. Time out: ethical reflections on medical disqualification of athletes in the context of mandated pre-participation cardiac screening. Br J Sports Med 2018;52:1207-10.

16 Centre FMAaR. Fifa pre-competition medical assessment (PCMA): Fédération Internationale de football association, 2020. Available: https://www.fifa.com/search/?q=PCMA

17 Hersh L, Salzman B, Snyderman D. Health literacy in primary care practice. Am Fam Physician 2015;92:118-24.

18 Formulas R. Automatic readability Checker (our free text readability consensus calculator): readability formulas, 2021. Available: https:// readabilityformulas.com/free-readability-formula-tests.php

19 Kessels RPC. Patients' memory for medical information. J R Soc Med 2003;96:219-22.

20 Zolnierek KBH, Dimatteo MR. Physician communication and patient adherence to treatment: a meta-analysis. Med Care 2009;47:826-34

21 Angelini P, Vidovich MI, Lawless CE, et al. Preventing sudden cardiac death in athletes: in search of evidence-based, cost-effective screening. Tex Heart Inst J 2013;40:148-55.

22 Berge HM, Andersen TE, Bahr R. Cardiovascular incidents in male professional football players with negative preparticipation cardiac screening results: an 8-year follow-up. Br J Sports Med 2019;53:1279-84.

23 KsB W, Mills Hv. Tottenham hotspur \& cowie (2015). 12 king's bench walk news \& articles [Internet], 2015. Available: https://www.12kbw. co.uk/news-articles/page/23/

24 Donovan-Kicken E, Mackert M, Guinn TD, et al. Sources of patient uncertainty when reviewing medical disclosure and consent documentation. Patient Educ Couns 2013;90:254-60.

25 Mitten MJ, Zipes DP, Maron BJ, et al. Eligibility and Disqualification recommendations for competitive athletes with cardiovascular abnormalities: Task force 15: legal aspects of medical eligibility and Disqualification recommendations: a scientific statement from the American heart association and American College of cardiology. $J$ Am Coll Cardiol 2015;66:2447-50.

26 Kroshus E, Garnett B, Hawrilenko M, et al. Concussion underreporting and pressure from coaches, teammates, fans, and parents. Soc Sci Med 2015;134:66-75.

27 Cusimano MD, Topolovec-Vranic J, Zhang S, et al. Factors influencing the underreporting of concussion in sports: a qualitative study of minor hockey participants. Clin J Sport Med 2017;27:375-80. 